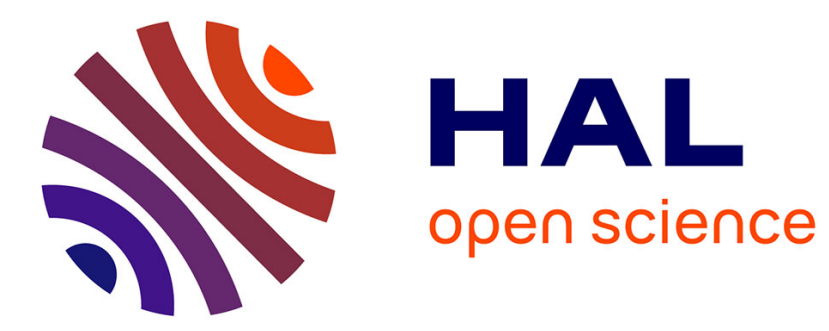

\title{
Self-Serving Dictators and Economic Growth
}

\author{
Daniel Haile, Abdolkarim Sadrieh, Harrie A.A. Verbon
}

\section{To cite this version:}

Daniel Haile, Abdolkarim Sadrieh, Harrie A.A. Verbon. Self-Serving Dictators and Economic Growth. Journal of Economic Behavior and Organization, 2008, 67 (3-4), pp.573. 10.1016/j.jebo.2007.09.004 . hal-00614683

\section{HAL Id: hal-00614683 \\ https://hal.science/hal-00614683}

Submitted on 15 Aug 2011

HAL is a multi-disciplinary open access archive for the deposit and dissemination of scientific research documents, whether they are published or not. The documents may come from teaching and research institutions in France or abroad, or from public or private research centers.
L'archive ouverte pluridisciplinaire HAL, est destinée au dépôt et à la diffusion de documents scientifiques de niveau recherche, publiés ou non, émanant des établissements d'enseignement et de recherche français ou étrangers, des laboratoires publics ou privés. 


\section{Accepted Manuscript}

Title: Self-Serving Dictators and Economic Growth

Authors: Daniel Haile, Abdolkarim Sadrieh, Harrie A.A. Verbon

PII: $\quad$ S0167-2681(07)00199-0

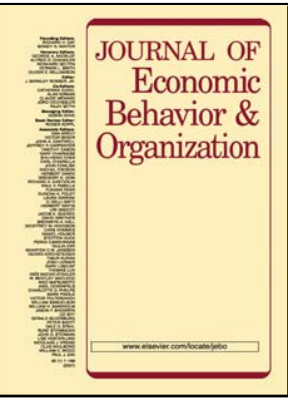

DOI: doi:10.1016/j.jebo.2007.09.004

Reference: JEBO 2150

To appear in: Journal of Economic Behavior \& Organization

Received date: $\quad$ 6-6-2006

Revised date: $\quad 12-9-2007$

Accepted date: $\quad$ 14-9-2007

Please cite this article as: Haile, D., Sadrieh, A., Verbon, H.A.A., Self-Serving Dictators and Economic Growth, Journal of Economic Behavior and Organization (2007), doi:10.1016/j.jebo.2007.09.004

This is a PDF file of an unedited manuscript that has been accepted for publication. As a service to our customers we are providing this early version of the manuscript. The manuscript will undergo copyediting, typesetting, and review of the resulting proof before it is published in its final form. Please note that during the production process errors may be discovered which could affect the content, and all legal disclaimers that apply to the journal pertain. 


\title{
Self-Serving Dictators and Economic Growth
}

Daniel Haile, Tilburg University, Department of Economics, Tilburg University, P.O. Box 90153, 5000 LE Tilburg, the Netherlands

Abdolkarim Sadrieh, University of Magdeburg, Faculty of Economics and Management, Postbox 4120, 39106 Magdeburg, Germany

Harrie A.A.Verbon, Tilburg University, Department of Economics, Tilburg University, P.O. Box 90153, 5000 LE Tilburg, the Netherlands

\begin{abstract}
We study the effect of fair institutions on growth. In our model, individuals are endowed with unequal entitlements to the economy's output. They can free-ride or cooperate. Cooperation is individually costly, but increases aggregate output and growth. Experimentally, we observe significantly less cooperation, when dictators chose high instead of low inequality. This effect is not observed when the degree of inequality is chosen randomly. Simple cross-country regressions provide basic macroeconomic support for interaction effects between the degree and the genesis of inequality. We conclude that economies granting equal opportunities are less likely to suffer retarded growth due to free-riding than economies with self-serving dictators.
\end{abstract}

JEL codes: C91, D60, K40, O40, P51

Keywords: inequality, fair procedures, corruption, dynamic public goods game, institutional design

\section{Corresponding author}

Harrie Verbon

Department of Economics, Tilburg University, P.O. Box 90153, 5000 LE Tilburg, the Netherlands

Telephone: +31 13 4662878; Telefax: +31 134663042; e-mail: h.a.a.verbon@uvt.nl

\section{Acknowledgements}

We are grateful for helpful comments from conference and seminar audiences at the ESA international meetings in Pittsburgh, the European Public Choice Society meeting at Aarhus, the Maastricht University, the University of Innsbruck, and at the Max-Planck Institute for Research in Economic Systems in Jena. Part of this paper was written when the last author was at the CES/Ifo institute in Munich. 


\section{Introduction}

The growth of an economy depends, amongst other factors, on the amount of effort that the individuals provide in the production and development processes. When individual effort contributions create positive externalities for the entire economy (e.g. through technological spillover, increased tax income, etc.), the added benefit typically is divided up according to the distribution of property rights in the economy. Since the provision of effort is costly and to some extent non-observable (or not easily verifiable), there is usually scope both for cooperative behavior that enhances economic output and for free-riding behavior that hampers it. If individuals in this framework condition their effort choices on social parameters such as the level or the genesis of income inequality, the societal configuration may have a significant impact on economic growth.

In fact, Knack and Keefer (1997) find empirical evidence for a negative correlation between income inequality and growth. They conjecture that inequality harms growth because it impairs "social capital," (i.e. trust in people and institutions). ${ }^{1}$ Glaeser et al. (2003), however, argue that inequality is not harmful for social capital per se, but only in connection with some form of "institutional weakness." They model a society with a weak legal system and show that inequality may substantially reduce the level of investments because investors fear the expropriation of their expected returns by the rich who can bribe their way out of the prosecution by the corrupt courts. Hence, the combination of inequality and a weak legal system impedes efficient investments, thus leading to low levels of economic growth. This

\footnotetext{
${ }^{1}$ Although the cross-section studies provide empirical insights on the macro level, they are bound to leave questions concerning the microeconomic foundations unanswered. For a critical assessment of the cross-section analyses and an overview of possible channels of interaction between inequality and growth see Aghion et al. (1999) as well as Barro (2000).
} 
link between inequality, corruption, and growth finds support in the numerous surveys in which business people sound their concern for corruption and preferential treatment (Lambsdorff 2002).

In this paper, we focus on the negative effect of the interaction of inequality and institutional structure on growth. Our idea is that the same level of inequality can affect cooperative behavior in different ways, depending on the circumstances under which it has historically emerged. When inequality in the distribution of property rights is perceived as resulting from the unfair actions of a few powerful agents ("self-serving dictators"), the level of trust in the society deteriorates, free-riding increases and the willingness of individuals to cooperate declines, but when inequality is perceived as resulting from a fair procedure, ${ }^{2}$ we conjecture that trust and cooperation are unaffected.

Typically procedures are deemed fair if they create a "level playing field" that ex-ante provides all individuals with an equal opportunity for success. In this sense, randomly drawing prizes from the same distribution is considered a fair procedure because it provides equal chances ex-ante while not (necessarily) providing equal payoffs ex-post (Bolton et al. 2005). Obviously, a fair random procedure is not equivalent to free market interaction. In the latter case, individual skills, knowledge, and information can decisively affect the outcomes. However, if we assume that the individual traits are randomly distributed, the outcomes of the free market interaction are also randomly distributed ex-ante and, thus, to some degree comparable to the outcomes of a fair random procedure not based on individual traits. In fact, Hoffmann et al. (1994) show that an unequal distribution of property rights (and outcomes) is

\footnotetext{
${ }^{2}$ Independent from our work Bolton et al. (2005) investigated the effect of the fairness of the procedure that is used for selecting outcomes. Their focus is on the acceptability of unfair outcomes, given the (non) existence of fair procedures for selecting the outcomes. Our focus is on the effect a procedure has on the willingness to cooperate in a dynamic environment
} 
more likely to be considered fair if it results from a skill-based competition that gives all parties equal opportunities. Apparently the distribution of individual traits is thought to be random and the market competition is considered to be a fair procedure.

We take three steps to find evidence for our conjecture. We first introduce and analyze a dynamic game that captures the main features of the situation that we have in mind. Next, we report a laboratory experiment of that game, comparing the degree of cooperation in the case when inequality is a consequence of unfair actions to the case where inequality results from a fair random procedure. Finally, we run a few simple regression analyses of macro data in the search of some basic empirical support for our main hypothesis.

The game we introduce is a dynamic 3-person 2-period game with one "rich" and two "poor" individuals. In each period, individuals choose either to cooperate (i.e. increase the total social product), to free-ride (i.e. increase the own relative payoff), or to destroy the current period's payoffs of all the individuals in the economy, including the own. Free-riding is the individually optimal action, while mutual cooperation leads to the efficient outcome. The destruction action is clearly dominated, but provides a strong means of punishment.

Apart from the destruction action, which is meant to represent all forms of social unrest including strikes, sabotage actions, or even civil wars, there are three main differences between our game and a standard public good game. First, unlike standard public good games in which the investments are taken out of the individual endowments, our endowments only represent property rights that define the portion of the social output to which each individual is entitled. Second, the investments in our game are made in terms of work effort that can either be invested in the total production output of the economy (i.e. in the public good) or can be "saved" to increase the (on the job) leisure of the individual (i.e. reducing effort cost is the private good). Finally, the third main difference to standard static public good games is 
that increasing the public good (i.e. the production output) has positive dynamic effects since the output level in each period depends not only on the work effort exerted in the period, but also on the output level of the previous period. The notion is that a high previous period output provides the economy with a high level of capital stock that enhances the productivity in the current period.

There is inequality in the model because the individual earnings from the social product are proportional to individual endowments (i.e. they are greater for the rich than for the poor). Hence, being poor in this game means having a smaller share of the property rights to the social output than the rich. Just as in Sadrieh and Verbon (2006), the degree of inequality is varied. The important new feature of this study is that, in one treatment, the degree of inequality is chosen by the rich individual (the dictator) before the interaction starts. Hence, in our dictator treatment we sometimes observe a high inequality economy DicHi (Ginicoefficient .6) and sometime a low inequality economy DicLo (Gini-coefficient .1), depending on the choice made by the rich individual. Our experimental control treatment consists of two settings where the inequality is fixed by nature: in NatHi the high inequality economy and in NatLo the low inequality economy are implemented at random by the experimenter.

Our main hypothesis is that the cooperation by the poor is on a much lower level when the high inequality setting is chosen by the rich (the dictator) than when it is implemented by the experimenters (by nature). In contrast, when the rich deliberately choose the low inequality setting, we expect that the poor engage in even more cooperation than in a low inequality setting fixed by nature. Hence, we expect the reciprocal behavior of the poor in the dictator treatment to lead to a clearly negative effect of inequality choice on growth, while in the nature treatment we expect to replicate the neutrality finding of Sadrieh and Verbon. 
The experimental results are in line with our three hypotheses. When implemented by nature (i.e. by a random draw), inequality has no effect whatsoever on the level of cooperation. In contrast, when implemented by the choice of the rich dictator, choosing high (low) inequality leads to a significantly lower (higher) level of cooperation by the poor than in the nature treatment. Hence, we find a strong and significantly negative effect of inequality on growth, but only when inequality results from deliberate actions of the rich dictator. ${ }^{3}$

Our experimental results suggest that the willingness to initiate and sustain cooperation in a society crucially depends on the historic process that created the distribution of wealth. This means that simply correlating inequality to growth may miss an important aspect of the issue, namely the genesis of inequality. We expect to find a negative correlation between inequality and growth only when inequality has emerged due to discriminating and corrupt actions of the rich and powerful, but not when it is the result of differences in capabilities and preferences in an otherwise just society. Thus, inequality arising in an economy that treats all individuals in an unbiased way and gives them equal opportunities should have a different effect on economic development than inequality arising in corrupt and politically biased societies. We provide basic empirical support for this hypothesis in a simple regression analysis in section 5. Preceding that section, we introduce our model in section 2 and report on the experiment in sections 3 and 4. Section 6 concludes.

\footnotetext{
${ }^{3}$ Our results seem related to the literature on reciprocal responses that asserts that an agent's response not only depends on the consequences, but also on the intentions of other agents' actions. Rabin (1993) introduces a first formal model that is enhanced by Dufwenberg and Kirchsteiger (2004). Blount (1995) and Falk et al. (2000) find more reciprocation to human than to the randomized first movers. Fehr and Rockenbach (2003) show that the level of positive reciprocity is higher when punishment is possible, but deliberately not chosen, than when punishment is not possible in the first place.
} 


\section{The Model}

We assume there are $n$ individuals $i=1, \ldots, n$ with capital endowments, $\omega_{i}>0$. All capital is productive, and individuals can generate a return on the total capital available by exerting effort $\sigma_{i}(i=1, \ldots, n$.$) . Effort can be interpreted as the time or attention an individual$ contributes to the production process. All individual's efforts are perfect substitutes in generating returns on capital (i.e. the marginal productivity of effort is the same for every individual). The efforts $\sigma_{i}$ that are exerted by the individuals $(i=1, \ldots, n$.) are aggregated to form total labor input in production. Total output $f(\omega, \sigma)=\Sigma \sigma_{i} \Sigma \omega_{i}$ is distributed in proportion to the capital endowments (i.e. the endowments are ownership rights to society's return on efforts). The individual's effort involves a cost (e.g. a decrease in utility due to the loss of leisure) that is borne by the individual himself. As in Aghion et al. the cost incurred by individual $i$ is proportional to total capital accumulated in the economy and the squared individual efforts, $c(\omega, \sigma)=\sigma_{i}^{2} \Sigma \omega_{i} / 2 .^{4}$ The payoff of individual $i$ at the end of a period is equal to his share $\omega_{i} / \Sigma \omega_{i}$ of the total product minus effort cost:

$$
\pi_{i}=\left(\omega_{i} / \sum_{j=1}^{n} \omega_{j}\right) f(\omega, \sigma)-c(\omega, \sigma)=\omega_{i} \sum_{j=1}^{n} \sigma_{\mathrm{j}}-\sigma_{i}^{2} \Sigma \omega_{i} / 2
$$

Notice that the individual effort choices have the character of voluntary contributions to a public good: all members of the society gain when an individual exerts productive effort, but the cost of exerting the effort is borne by the individual alone. Moreover, if no individual contributes to the generation of a return on investment (i.e. $\sigma_{\mathrm{j}}=0, j=1, \ldots, n$ ) everyone's 
gross and net return will be zero. It can readily be calculated that for any vector of contributions $\sigma_{\mathrm{j}}$ by the other individuals, the best response of player $i$ is

$$
\sigma_{\mathrm{i}}=\omega_{i} / \sum_{j=1}^{n} \omega_{\mathrm{j}}
$$

Notice that, according to equation (2), it will always be optimal to provide effort (i.e. $\sigma_{i}>0$ ), irrespective of the effort provided by the others. Thus, the equilibrium will not be at a corner of the action space. In our experiment, subjects had to choose between playing the equilibrium strategy or playing cooperatively. Regarding the latter, we can formulate a socialwelfare function and maximize this function with respect to individual efforts. As is wellknown, the choice of a social-welfare function depends on a number of social value judgments. Although the details of any given specification may affect behavior to some extent, we believe that the main impact of any form of cooperative play stems from the mutual increase in payoffs. Hence, avoiding the discussions on value judgments, we have chosen an underlying cooperative structure that is simple to implement experimentally and that leads to substantial payoff increases for all parties when compared to equilibrium. The following specification, in which a constant amount of effort (.25) is added to every player's equilibrium effort, satisfied these criteria:

$$
\sigma_{i}^{C}=\sigma_{i}+0.25
$$

Next period's endowment is the discounted sum of this period's endowment and payoff that is defined by (1), that is, $\omega_{i}^{t+1}=\rho\left(\pi_{i}+\omega_{i}^{t}\right)$ where $\rho$ is a discount factor. (For the experiment,

\footnotetext{
${ }^{4} \mathrm{We}$ introduce this cost function because it generates a convenient description of equilibrium behavior. The interpretation for this specification, apart from the familiar U-shaped form, is that as the economy becomes more prosperous, the utility loss of providing a certain amount of effort increases.
} 
we set $\rho=2 / 3$ ). In the next period, with the updated wealth levels, the individual again must decide whether to play the stage game Nash equilibrium strategy, as defined by (2), or to play cooperatively, as defined by (3). The payoff of the new period is again determined by (1), but now for the updated values of the individual endowments. The total payoff of each individual is obtained by adding up all period payoffs. The total payoff, thus, indicates the absolute growth an individual has realized on his initial endowment. The individual rate of growth can then be obtained by simply dividing the total payoff by the initial endowment.

Social unrest is one possible response of the poor to inequality. Especially in dictatorial and corrupt societies, violent distributive struggles regularly erupt that often destroy substantial parts of the economy's productive capital. It is, of course, difficult to model the possibility of social unrest in laboratory experiments. However, it is possible to give subjects the possibility to bring about payoff consequences that are similar to those arising from violent social unrest. To do so, we give every individual the option to destroy the entire current production of the economy, after each period of the game. If destruction is chosen by any single individual, the payoffs of all individuals for the current round are zero and the endowments retain the original previous period size. In particular, if in all periods at least one member chooses the destruction option, perfect income equality is established because the total payoff of every individual is zero. ${ }^{5}$ Since the destruction choice is always strictly dominated by nondestruction, the only subgame perfect equilibrium of the game consists of all players choosing stage game equilibrium strategies (as in equation (2)) without choosing the destruction action at any point in the game.

\footnotetext{
${ }^{5}$ A number of experimental studies have shown that subjects are willing to incur a substantial loss, if necessary, in order to avoid a large income inequality. For example, in ultimatum games (Güth 1995, Roth 1995), responders reject up to $40 \%$ of the benefits of trade just to avoid an unfair $40 \%-60 \%$ division of the surplus. The phenomenon that subjects are willing to pay a high price to reduce income inequality is observed not only in the ultimatum game, but also in other games (see e.g. Abbink et al. 2000, Bosman and van Winden 2002).
} 


\section{Experimental Conditions and Procedures}

The dynamic effort provision game described in the previous section was played in four experimental conditions. In every condition, an observation consisted of 3 players (that are called "an economy" in the following) with a total endowment of 300 . In the low inequality setting, the rich had an endowment of 120 , while the endowment of the poor was 90 . In the high inequality setting, the endowments were 220 for the rich and 40 for the poor. In each session of the nature treatment, the experimenter determined one of the two possible distributions of endowments and informed the subjects before the game started. In the dictator treatment, the experimenter informed the subjects that the rich individual will choose one of the two possible distributions before the game starts. After this choice was made the subjects were informed on the chosen distribution of endowments and the game started. This method of determining the initial endowments was the only difference between the treatments. Combining the method of distribution selection (nature vs. dictator) with the two possible outcomes (low inequality vs. high inequality) gives us the four experimental conditions NatLo, NatHi, DicLo, DicHi that are summarized in table 1.

In all conditions, a two-period version of the dynamic game was played. In each period, players first chose their effort levels. They could choose to act cooperatively or to free-ride (i.e. play Nash equilibrium strategy). After all effort choices were made, subjects received feedback on all choices and payoff consequences in their economy. Then, each subject was given the opportunity to destroy the period's payoffs of all individuals in the economy (including their own payoff). In the second period of the game, the same decisions had to be taken. After the second period had been completed, subjects received their final payoffs. All actions were presented to the subjects in neutral terms: the free-riding and cooperative actions were called "A" and "B," respectively, and the payoff destruction action was called "reset." 
Table 1 - Experimental Conditions

\begin{tabular}{cccccc}
\hline \hline Treatment & $\begin{array}{c}\text { Distribution is } \\
\text { determined }\end{array}$ & $\begin{array}{c}\text { Inequality level } \\
\text { (Gini coefficient) }\end{array}$ & $\begin{array}{c}\text { endowments } \\
\text { (rich, poor, poor) }\end{array}$ & $\begin{array}{c}\text { number of } \\
\text { subjects }\end{array}$ & $\begin{array}{c}\text { Number of } \\
\text { independent } \\
\text { observations }\end{array}$ \\
\hline NatLo & by nature & Low $(.10)$ & $(120,90,90)$ & 21 & 7 \\
NatHi & by nature & High $(.60)$ & $(220,40,40)$ & 24 & 8 \\
DicLo & by dictator & Low $(.10)$ & $(120,90,90)$ & 24 & 8 \\
DicHi & by dictator & High $(.60)$ & $(220,40,40)$ & 24 & 8 \\
\hline \hline
\end{tabular}

All sessions took place at the CentERlab at Tilburg University. The subjects were student volunteers who were hired via public recruitment on campus. Most of them were first year students in economics, business, and social sciences. Upon entering the laboratory, subjects were asked to draw a card from a covered deck. The randomly drawn card determined the table number at which they were seated. The matching of the tables into economies and the roles of the players had been randomly determined before the experiment started.

The game was extensively explained to the subjects. After subjects had read the instructions (reproduced in Appendix A) ${ }^{6}$, they were asked to answer two guided practice questions that tested their understanding of the game. All subjects successfully solved the control questions. In total, 93 subjects (forming 31 economies) participated in the experiment. The distribution of economies over the treatments is given in Table 1. Incidentally, exactly one half of the rich subjects in the dictator treatment opted for the low inequality and one half opted for the high inequality distribution. Each subject participated only in one session. All sessions were held in May, June, and September 2002.

The experiment was run with paper and pencil. Students were seated in cubicles and were asked not to communicate. The payoff information was presented to subjects in tables (see 
Appendix B). The tables were organized so that each subject saw the own payoffs in the first column and the payoffs of the other players in the other two columns. Using the tables, the subjects could quickly "look forward" through both periods of the dynamic game.

Subjects did not know the identity of the other subjects in their economy. This was guaranteed because there were always more than three (usually 24) subjects present in each session. The decision sheets (see Appendix C) were administered to all subjects at once. After subjects made their decisions, these were recorded by the experimenters. Only after all subjects had made their first decision did the experimenters fill-in the first-period choices of the members of the corresponding economy on each subject's decision sheet. Next all subjects were given the opportunity to decide whether to destroy the output of the economy. (This option is called "Reset" on the decision sheet). Again, the decisions were recorded and only passed on after all subjects had made a decision. The procedure was replicated for period 2. Note that the decision sheet refers to the relevant part of the payoff sheet in every phase of the game. Hence, subjects could easily track the history of play.

No explicit time limit was given to subjects. Nevertheless, the duration of no session exceeded the two hours that had been announced on the posters. The average duration of a session was about one hour and twenty minutes. At the end of the experiment, subjects received a monetary payment consisting of a show-up fee of 3 Euros plus the experimental payoff that was converted at a rate of 20 Eurocents per point. Payments to the subjects, including show-up fee, ranged from 4 to 44.6 Euros, with an average of 10.10 Euros (1 Euro exchanged at the rate of about $\$ 1$ at the time).

\footnotetext{
${ }^{6}$ Appendix A containing the instructions used in the implementation of the experiment can be found in the online version at the JEBO website.
} 


\section{Experimental Evidence}

Table 2 contains information on the individual choices regarding cooperative effort and destruction in both periods of the game. In the first part of the table, the cooperative effort choices of rich and poor individuals are given for the first period.

Table 2: Individual choices in the $1^{\text {st }}$ and $2^{\text {nd }}$ periods ${ }^{\text {a) }}$

\begin{tabular}{|c|c|c|c|c|c|c|}
\hline \multicolumn{7}{|c|}{ 1. First period cooperative choices } \\
\hline \multirow[b]{2}{*}{ Treatment } & \multicolumn{2}{|l|}{ Rich } & \multirow{2}{*}{$\begin{array}{c}\text { Dictator-Nature } \\
\text { difference }^{b)}\end{array}$} & \multicolumn{2}{|l|}{ Poor } & \multirow{2}{*}{$\begin{array}{c}\text { Dictator-Nature } \\
\text { difference }^{b}\end{array}$} \\
\hline & Dictator & Nature & & Dictator & Nature & \\
\hline Low inequality & $2 / 8$ & $3 / 7$ & \multirow{3}{*}{$\begin{array}{c}\text { n.s. } \\
*\end{array}$} & $10 / 16$ & $5 / 14$ & $*$ \\
\hline High inequality & $1 / 8$ & $5 / 8$ & & $2 / 16$ & $7 / 16$ & $* *$ \\
\hline Low-High difference ${ }^{\text {b) }}$ & n.s. & n.s. & & $* * *$ & n.s. & \\
\hline \multicolumn{7}{|c|}{ 2. First period destruction choices } \\
\hline Low inequality & $0 / 8$ & $0 / 7$ & n.s. & $0 / 16$ & $0 / 14$ & n.s. \\
\hline High inequality & $0 / 8$ & $1 / 8$ & n.s. & $1 / 16$ & $1 / 16$ & n.s. \\
\hline Low-High difference $^{\text {b) }}$ & n.s. & n.s. & & n.s. & n.s. & \\
\hline \multicolumn{7}{|c|}{ 3. Second period cooperative choices } \\
\hline Low inequality & $2 / 8$ & $1 / 7$ & \multirow{3}{*}{$\begin{array}{l}\text { n.s. } \\
\text { n.s. }\end{array}$} & $3 / 16$ & $4 / 14$ & \multirow{3}{*}{$\begin{array}{l}\text { n.s. } \\
* *\end{array}$} \\
\hline High inequality & $1 / 8$ & $3 / 8$ & & $1 / 16$ & $6 / 16$ & \\
\hline Low-High difference $^{\text {b) }}$ & n.s. & n.s. & & n.s. & n.s. & \\
\hline \multicolumn{7}{|c|}{ 4. Second period destruction choices } \\
\hline Low inequality & $1 / 8$ & $0 / 7$ & n.s. & $1 / 16$ & $1 / 14$ & n.s. \\
\hline High inequality & $0 / 8$ & $0 / 8$ & n.s. & $2 / 16$ & $1 / 16$ & n.s. \\
\hline Low-High difference ${ }^{\text {b) }}$ & n.s. & n.s. & & n.s. & n.s. & \\
\hline
\end{tabular}

a) The fractions $\mathrm{i} / \mathrm{j}$ indicate the number $\mathrm{i}$ of cooperative or destruction choices out of a total of $\mathrm{j}$ observations.

b) All differences are tested using Fisher's exact test with a two-tailed alternative hypothesis, where two-tailed significance levels are indicated as follows: $* * *=.02, * *=.05, *=.10$, or $\mathrm{n} . \mathrm{s} .=$ not significant.

We first check whether the neutrality result found by Sadrieh and Verbon is replicated (i.e. whether the inclination to cooperate by rich and poor individuals is neutral to the degree of inequality in the nature treatment). According to Table 2, in the nature treatment, 3 out of 7 low inequality economies show cooperative effort choices by the rich, while cooperation is exhibited for the high inequality economies in 5 out of 8 cases. This small difference 
obviously is not statistically significant. Likewise, the difference in cooperative efforts provided by the poor (5 out of 14 in NatLo and 7 out of 16 in NatHi economies) is not significantly different. This gives support to the finding that inequality (when it emerges from a fair, but random process) is neutral and does not have any growth-enhancing or growthdecreasing effects. This leads to our first result.

Result 1: Inequality given by nature (a fair, but random process) does not have an effect on the level of cooperation by rich and poor individuals.

Let us now turn to the dictator treatment. Remember that in that case the rich individual determines which distribution should be put in place before effort choices are made. Notice from table 2 that the rich are not much affected by their own choice of inequality: Only 2 of the 8 rich who choose low inequality as dictators also choose the cooperative action. This ratio is not significantly different from the ratio of one out of the 8 rich dictators who chooses high inequality and cooperation. The behavior of the poor, however, is significantly affected by the distribution that the dictator chooses: While 10 of 16 poor provide cooperatively high effort when low inequality has been chosen, only 2 of 16 cooperate when high inequality has been chosen. This difference in the number of cooperative plays is highly significant $(\alpha \leq .01$; two-tailed). Thus, if the dictator chooses low inequality, the poor reciprocate by putting more effort into generating returns on the capital stock. Hence, if the poor and powerless in an economy know that those who are in power have actively reduced the inequality, then they provide more effort to the benefit of the entire economy. On the other hand, dictators choosing high inequality seem to signal a self-serving attitude that induces a large majority of the poor to behave non-cooperatively. This is laid down in our second result.

Result 2: In the dictator treatment the poor will provide more cooperative effort under low inequality than under high inequality. 
A key issue in this paper is the question of whether the way inequality arises has an effect on individual behavior. We can analyze this issue by comparing the effort choices in the dictator settings to the effort choices in the corresponding nature settings. Comparing across columns in Table 2 shows that under low inequality, the behavior of the rich is the same, no matter whether the distribution was randomly selected or was an explicit own choice: 3 of 7 rich in NatLo and 2 of 8 rich in DicLo provide cooperative efforts. In the case of high inequality, however, the rich are significantly ( $\alpha \leq .10$; two-tailed) more cooperative in NatHi, where the income distribution is set by nature (5 out of 8 ), than in $\mathrm{DicHi}$, where they chose high inequality distribution themselves ( 1 out of 8$)$. Of course, there may be a selection bias here because the rich who choose high inequality can be expected to be less cooperative.

For the poor the picture is even clearer. Under high inequality, the poor are significantly less cooperative ( $\alpha \leq .05$; two-tailed) if the distribution has come about by willful choice of the rich dictator than if the distribution has been determined by nature: 2 of 16 poor cooperate in DicHi, while 7 of 16 do so in NatHi. Under low inequality we find the reverse: the poor are significantly ( $\alpha \leq .10$; two-tailed) more cooperative when the rich choose the low inequality distribution than when it is put in place by nature (10 of 16 poor cooperate in DicLo, but only 5 of 14 poor cooperate in NatLo). This leads to our third result.

Result 3a: The poor are more cooperative when low inequality has been set by the dictator instead of by nature.

Result 3b: The poor are less cooperative when high inequality has been set by the dictator instead of by nature.

Notice that result $3 \mathrm{~b}$ survives in the second period, but result $3 \mathrm{a}$ does not. As can be seen in the third part of Table 2, the case of poor in the DicLo treatment is the only case in which the general level of cooperation actually changes dramatically in the second period. In all other 
cases, we observe about the same level of cooperation in the second period as we had observed in the first period. Thus, while the treatment difference in the low inequality setting disappears in the second period, the significant treatment difference in the high inequality setting persists. One plausible reason why cooperation decreases dramatically only in the DicLo case is that many of the poor choosing the cooperative action were disappointed that the dictators who chose the low inequality did not also choose the cooperative action.

Result 3 makes clear that poor individuals reciprocate the "kind" act of a dictator choosing low inequality by exerting high productive efforts, but punish the "unkind" act of choosing high inequality by exerting low productive efforts. Note that the "punishment" of providing uncooperative efforts is not costly to the punisher because it is the best response strategy. The destruction option that all individuals in the economy have at the end of each period provides a quite different (and very costly) punishment possibility. If any individual chooses this option, the current period payoffs will be lost for all individuals. We expected that in particular poor subjects who feel that they have been unfairly treated by the dictator's choice of the high inequality will use the sabotage action to "equalize" payoffs. From the second part of Table 2 it is clear that our expectation is not borne out by the data. Actually, this option is used rarely. Only 3 of the 93 individuals use this option in the first period, and they are dispersed over the treatments. ${ }^{7}$ In the fourth part of Table 2, we see that one rich and 5 poor individuals choose to destroy the returns of the second period. Obviously, destruction in this stage has no "educational" effect anymore, but it may be used as punishment because it

\footnotetext{
${ }^{7}$ Looking at the individual choices in the cases in which destruction took place in the first period, we see the following. In the case where the rich individual chose destruction, the first period choice was BAA (where B indicates cooperation, A indicates Nash effort, and the choice of the rich is given first). Apparently the rich was disappointed that both poor chose A. In another case, one of the poor chose destruction, even though the dictator, who had chosen high inequality, showed "remorse" by choosing B in the first period. In the third case, the cooperating poor chose destruction apparently to punish the other poor who had chosen to free-ride in a $\mathrm{NatHi}$ session in which the rich had also chosen to cooperate.
} 
affects the final payoffs. ${ }^{8}$ Apparently, almost all rich individuals choose to safeguard the payoff that they have generated, while some of the poor individuals care less for their final payoffs and remain willing to punish others. ${ }^{9}$ It seems interesting that in three of the five DicHi economies in which one of the subjects chooses the cooperative effort level, a destruction of the returns occurs. Apparently, when the dictator opts for high inequality, cooperation frequently is followed by destruction because cooperation by one player tends to stay an isolated act.

Finally, it is interesting to observe that due to the low number of cooperative choices by the poor in DicHi economies, dictators choosing high inequality earn significantly less than the dictators choosing low inequality in DicLo. Table 3 shows that the difference in payoffs is not only significant, but also substantial: while the dictators choosing high inequality on average earn 43.13 experimental currency units, those choosing low inequality earn 77.50 on average. Moreover, Table 3 shows that the dictators who deliberately choose high inequality in DicHi also earn significantly and substantially less than the rich, who are put in the high inequality setting by chance in NatHi. Note, however, that the poor in DicHi do not earn significantly less than those in NatHi, even though the average earnings are slightly lower. Obviously, the Dictator-Nature distinction is not as crucial for the payoff of the poor as the extent of property rights that are given to them (i.e. the low- versus high-inequality distinction).

\footnotetext{
${ }^{8}$ It might be noticed here that in no economy was the destruction option chosen twice.

${ }^{9}$ The one rich individual who chose to destroy was a very cooperative one. He opted for the low inequality distribution first and then chose the cooperative B twice. After he saw that neither of the two poor subjects chose to cooperate in the second period, he decided to destroy their (and his own) returns.
} 
Table 3: Payoffs ${ }^{\text {a) }}$

\begin{tabular}{|c|c|c|c|c|c|c|}
\hline \multirow[b]{2}{*}{ Treatment } & \multicolumn{2}{|l|}{ Rich } & \multirow{2}{*}{$\begin{array}{l}\text { Dictator-Nature } \\
\text { difference }^{\text {b) }}\end{array}$} & \multicolumn{2}{|l|}{ Poor } & \multirow{2}{*}{$\begin{array}{l}\text { Dictator-Nature } \\
\text { difference }^{\text {b) }}\end{array}$} \\
\hline & Dictator & Nature & & Dictator & Nature & \\
\hline Low inequality & 77.50 & 73.57 & n.s. & 55.06 & 60.50 & n.s. \\
\hline High inequality & 43.13 & 86.13 & $* *$ & 21.94 & 27.50 & n.s. \\
\hline Low-High difference ${ }^{\text {b) }}$ & $* * *$ & n.s. & & $* * *$ & $* * *$ & \\
\hline
\end{tabular}
a) Average payoffs are displayed in experimental currency units.
b) All differences are tested using the Mann-Whitney U-test with a two-tailed alternative hypothesis, where two-tailed significance levels are indicated as follows: $* * *=.02, * *=.05, *=.10$, or $\mathrm{n} . \mathrm{s}$. $=$ not significant.

Figure 1 shows the observed growth rate of every economy in the experiment normalized to Nash equilibrium growth. ${ }^{10}$ Bars above (below) the zero-line indicate economies that realized growth that was higher (lower) than equilibrium growth. The average growth rate in DicHi is substantially lower than the average growth rates of the other treatments. This comes as no surprise since growth is positively correlated to the number of cooperation choices, which is very low in DicHi.

In the dictator treatments positive growth rates are obtained in 2 high inequality economies and 5 low inequality economies. In 3 high inequality economies sizable negative growth rates are observed, while this is the case in only 1 low inequality economy. As a result of these differences, the average growth rate is clearly positive at 0.13 in the low inequality setting, while it is negative at -0.07 and significantly lower in the high inequality setting (MannWhitney U-test at $1 \%$, one-tailed). In the nature treatments, positive growth rates are observed in 6 low and in 5 high inequality economies. Negative growth rates are observed in 3 high and in 1 low inequality economy. Apparently, in the nature treatment the effect of inequality on growth is inconclusive.

\footnotetext{
${ }^{10}$ We derive the normalized growth rate by subtracting the Nash equilibrium growth rate, which occurs, if all individuals in all periods play their Nash equilibrium strategies, from the observed growth rate.
} 

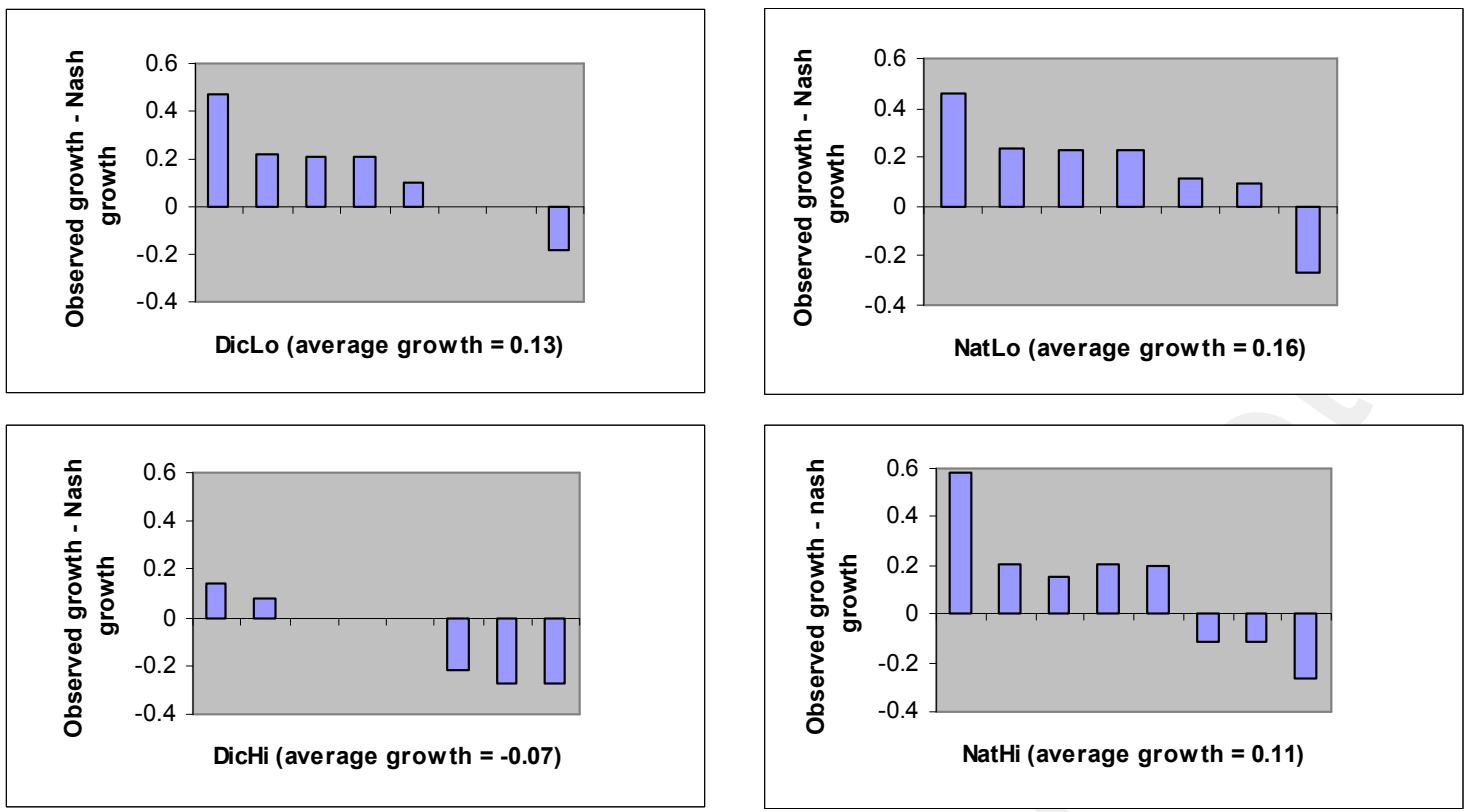

Figure 1 - Total growth for each economy and each treatment*

*) Each bar represents an independent observation of growth per economy, sorted in a descending order.

Comparing the nature and dictator treatments, it appears that the differences in growth for given low inequality are only minor: in the nature treatment 6 out of 7 economies realize positive growth rates, while this holds for 5 out of 8 economies in the dictator treatment. As a result, the average growth rate is only slightly and insignificantly lower in the dictator than the nature treatment: 0.13 compared to 0.16 , correspondingly. In the high inequality setting, however, the differences are clearly discernible: 5 out of 8 economies in the nature treatment, but only 2 out of 8 economies in the dictator treatment realize positive growth rates with average growth rates of 0.11 and -0.07 , correspondingly. The treatment difference is sizable and significant (Mann-Whitney U-test at 1\%, one-tailed). This leads to our fourth result.

Result 4: Low inequality leads to higher growth than high inequality in the dictator treatment. No such effect can be observed in the nature treatment. 


\section{Empirical evidence on the growth-inequality relationship}

Our experimental results suggest that when free-riding behavior can harm economic development, the adverse effect of inequality on growth depends on the interaction of the degree and the genesis of inequality. In this section, we present very simple cross-section regression analyses that provide some rather basic evidence for the external validity of our experimental finding ${ }^{11}$. Checking our main hypothesis requires a measure of the genesis of inequality to be included in a standard regression of inequality on growth. In principle, the required variable should represent an evaluation of the "fairness" of the procedure (or the institutions) that historically led to the observed degree of inequality. If the procedure were fair, then we expect growth to be unaffected by inequality. If it were unfair, we expect to observe a strong negative correlation between inequality and growth.

Obviously, while in the lab the fairness of the procedure can be controlled almost perfectly, there is no simple way to assess the genesis of inequality across countries. In actual fact, institutional weakness or strength of a country is a many-dimensional concept, witnessing the many indicators measuring institutional quality that are around to date ${ }^{12}$. In order to get an impression to what degree our experimental results are supported by macro data, we experimented with two indicators, respectively an indicator that focuses on one particular aspect and an indicator that encompasses several aspects of institutional weakness. The focused proxy for institutional quality is the degree of corruption in a country. People might perceive the genesis of inequality as especially unfair in societies in which a high degree of

\footnotetext{
${ }^{11}$ An analogous exercise was conducted by Glaeser et al. who regress GDP growth on inequality and on a binary variable indicating whether a country has a "strong legal system" or not. They find that: "Inequality is bad for growth, but only in countries with poor rule of law" (p. 215).

12 For example, Kaufmann et al. (1999) mention at least 31 different indicators that have been used in the empirical growth literature.
} 
corruption governs economic activities. If corruption is indeed a good proxy, then we should observe that the adverse effect of inequality on growth mainly runs through the interaction of inequality and corruption. The other index of institutional quality is composed of several different institutional variables taken from Kaufmann et al. The advantage of using the latter measure in a growth regression is that as several variables are codetermining its value, the endogeneity problem will not be much of an issue. With a more focused variable such as corruption an endogeneity problem might exist, however, for instance if in poor low-growth countries corruption is commonly used as a means to complement individual incomes, or if corruption is also affecting inequality (Li et al., 2000).

The dependent variable in our regressions is the GDP growth per capita over the period 19912001 and is taken from the World Bank's "World Development Indicators". ${ }^{13}$ We use an average over a relatively long period (ten years) to capture the long-run characteristics of the economies and to avoid cyclic short term effects as far as possible. As a measure of inequality we use Gini coefficients. This measure ranges from 0 (complete equality) to 100 (complete inequality). An issue that has received considerable attention in the literature is whether inequality of income or inequality of assets is the factor underlying growth differences between countries. To circumvent this debate we present results with income inequality and asset inequality, respectively. For the former measure we took data on household income inequality constructed by Galbraith and Kum (2005). ${ }^{14}$ For the latter measure, the initial distribution of land is commonly taken (see, e.g., Deininger and Olinto 2000 and Lundberg and Squire 2003 from which sources we extract the FAO data that we use). We regress growth rates on measures of inequality. However, as is well known, such an

\footnotetext{
${ }^{13}$ For details see the website: www.worldbank.orghttp://www.worldbank.org/data/countrydata/countrydata.html

${ }^{14}$ These data are claimed to be an improvement on the well-known data set developed by Deininger and Squire (1996).
} 
exercise can be plagued by an endogeneity bias as growth can also affect inequality in many ways. Fortunately, Lundberg and Squire show that in a reduced-form growth can be written as a function of the initial inequality in land distribution. This provides us with an additional argument for presenting results with the initial distribution of land as a measure of inequality because we can check whether the endogeneity bias distorts our results. Finally, we experiment with a number of control variables that are frequently used in the empirical growth literature. We include the initial GDP ("initial Y" in Table 4) to take care of the catching-up effect by economies starting at low GDP levels; the investment-GDP ratio $(\mathrm{Inv} / \mathrm{Y})$ and the relative amounts of money spent on education ("Educate" in Table 4) both capture conventional causes for growth and provide an indication of the sectoral structure of the economy. ${ }^{15}$ With these variables we are able to construct a data set for about 80 countries.

Note that in spite of the above precautions, we see the evidence provided here only as indicative for the empirical prevalence of the conjectured effect. A comprehensive empirical analysis would be clearly beyond the scope of our simple analysis and include a number of additional issues such as the question of inter-temporal effects that are neglected in our crosssection analysis. We analyze how institutional quality and inequality interact in a comparison across countries in a specified period (i.e. the 1990s). This is in line with our experimental set-up where we compare different "economies" at the same time, but obviously, our

\footnotetext{
15 The observations on the control variables GDP and investment were taken from the World Bank's World Development Indicators. Education is defined by total enrollment in a specific level of education, regardless of age, expressed as a percentage of the school population corresponding to the same level of education in a given school-year. Source: UNESCO - Education Indicator -Category Participation (www.unesco.org).
} 
empirical results do not warrant policy conclusions as to the effect of redressing inequality and improving institutional quality within a country over time. ${ }^{16}$

First, we show the effect of corruption on growth ${ }^{17}$. The corruption index that we use is constructed by Transparency International. ${ }^{18}$ The index, indicated by "Corrupt" in Table 4, describes the level of perceived corruption in each country using a collection of corruption and political risk indexes for the 1990s. We transferred the originally negative score into the range from 0 (low corruption) to 10 (high corruption) and took the average over the period 1995-2000.

Table 4 displays our regression results for six variants of the regression model and, for each model, the effect of inequality is captured by a Gini coefficient based on income (indicated by Income in the table) and the distribution of land (indicated by Land). The simple regressions in the rows (1) produce the effect of only inequality as an explanatory variable. Both asset and income inequality appear to exert the negative effect that is commonly found in cross-section studies.

The second regressions in rows (2) add our corruption measure. If the income inequality measure is used, the quantitative effect of inequality is cut down by one half and made

\footnotetext{
${ }^{16}$ As we do not employ time series, we remain silent on the issue of growth over time. Introducing the time dimension makes it inevitable to take more explicit account of changes in the structure of the economy because the relationship between inequality and growth is known to depend on the development of, in particular, the agricultural sector vis-à-vis the industrial sector (see Aghion et al.). Moreover, if we add time series data to our cross-section data, we need to pay attention to the separation of country-specific from time-specific effects and to decide whether these effects are of a stochastic nature. Finally, because the Gini coefficients used are relatively stable over time within countries (see Deininger and Squire), we would need (especially for developing countries) infeasible long time series to get enough variation of inequality over time.

17 The effect of corruption on growth was first measured by Mauro (1995), who finds an adverse effect of corruption. Ehrlich and Lui (1999), in a somewhat more elaborate model, also find significant adverse effects of corruption variables on growth. Neither paper, however, includes an inequality measure in the analysis. Li et al. include inequality and consider the effect of corruption on inequality. However, they do not include any possible interaction effects of inequality and corruption on growth.

${ }^{18}$ For details see the website: http://www.transparency.org/cpi/2002/cpi2002.en.html
} 
insignificant. If we use land inequality the addition of corruption decreases the effect by $10 \%$, but the effect remains significant. This suggests that corruption and income inequality may not be measured independently of each other, while if land inequality is used the measure of corruption and inequality are apparently orthogonal. Rows (3) add the controls as explanatory variables into rows (1). The explained variance increases substantially, but relative to rows (1) the direction of the effect of inequality does not change and remains significant, although the quantitative effect of inequality decreases by about a third. The bias these (and possibly other omitted) controls are exerting on the parameter of the inequality measures should, therefore, not prevent us from interpreting the empirical results.

Rows (4) add controls as explanatory variables into rows (2). Interestingly, compared to rows (2) income inequality regains its explanatory power, while compared to rows (3), where corruption is left out, the effect of inequality is almost the same. Apparently, some of the correlation between income inequality and corruption is neutralized by introducing the controls. If we use the distribution of land as the inequality measure, the effect of inequality on growth can be measured independently of corruption in all cases. Both the coefficients of inequality and corruption have the expected negative signs and have increased compared to rows (2). The explanatory power increases compared to all regressions in rows (1)-(3).

The regressions in rows (5) include an interaction term between inequality and corruption, indicated by $\mathrm{C}^{*}$ Gini. Once again, the explanatory power of the regression increases. The coefficient for the interaction term takes on a negative and highly significant value, but the coefficients for inequality and corruption have changed their signs and are no longer significant, thus supporting the result that the interaction between inequality and corruption is more decisive for growth than either of the two variables separately. However, the regressions also indicate that in the absence of corruption, inequality actually can have a growth 
enhancing effect. This is in line with theories that predict growth to be positively correlated to inequality due to the higher marginal propensity of the rich to save ${ }^{19}$, so that inequality can have a positive investment effect and a negative social capital effect, as has been discussed in the field before (see Aghion et al., Barro). Finally, the positive inequality-growth relationship is empirically non-significant in our regressions, however. In the regressions (6), we drop all non-significant variables. Then we are left with the result that under high corruption (index $=10$ ) there will be a significant negative effect of inequality on growth. Under low corruption (index $=0$ ), however, the degree of inequality is irrelevant to growth.

Table 4. Inequality, Corruption, and Growth

\begin{tabular}{|c|c|c|c|c|c|c|c|c|c|}
\hline & & Constant & Gini & Corrupt & $\mathrm{C}^{*}$ Gini & Initial Y & Inv/Y & Educate & Adj. $\mathrm{R}^{2}$ \\
\hline (1) & Income & $\begin{array}{c}5.704 \\
(1.289)\end{array}$ & $\begin{array}{l}-0.102 \\
(0.032)\end{array}$ & & & & & & 0.13 \\
\hline (1) & Land & 4.578 & $\begin{array}{l}-0.040 \\
(0.012)\end{array}$ & & & & & & 0.19 \\
\hline (2) & Income & 5.094 & $\begin{array}{l}-0.050 \\
(0.033)\end{array}$ & $\begin{array}{l}-0.271 \\
(0.083)\end{array}$ & & & & & 0.25 \\
\hline (2) & Land & 5.132 & $\begin{array}{l}-0.035 \\
(0.012)\end{array}$ & $\begin{array}{l}-0.151 \\
(0.069)\end{array}$ & & & & & 0.24 \\
\hline (3) & Income & $\begin{array}{c}3.314 \\
(1.644)\end{array}$ & $\begin{array}{l}-0.071 \\
(0.031)\end{array}$ & & & $\begin{array}{c}0.005 \\
(0.039)\end{array}$ & $\begin{array}{c}0.139 \\
(0.053)\end{array}$ & $\begin{array}{c}0.008 \\
(0.010)\end{array}$ & 0.36 \\
\hline (3) & Land & $\begin{array}{c}3.140 \\
(0.741)\end{array}$ & $\begin{array}{l}-0.032 \\
(0.010)\end{array}$ & & & $\begin{array}{l}-0.044 \\
(0.034)\end{array}$ & $\begin{array}{c}0.208 \\
(0.046)\end{array}$ & $\begin{array}{c}0.020 \\
(0.009)\end{array}$ & 0.52 \\
\hline (4) & Income & $\begin{array}{c}7.656 \\
(1.780)\end{array}$ & $\begin{array}{l}-0.077 \\
(0.029)\end{array}$ & $\begin{array}{l}-0.411 \\
(0.121)\end{array}$ & & $\begin{array}{l}-0.132 \\
(0.059)\end{array}$ & $\begin{array}{c}0.117 \\
(0.045)\end{array}$ & $\begin{array}{l}-0.004 \\
(0.008)\end{array}$ & 0.44 \\
\hline (4) & Land & $\begin{array}{c}4.636 \\
(1.439)\end{array}$ & $\begin{array}{l}-0.034 \\
(0.010)\end{array}$ & $\begin{array}{l}-0.272 \\
(0.132)\end{array}$ & & $\begin{array}{l}-0.128 \\
(0.054)\end{array}$ & $\begin{array}{c}0.185 \\
(0.047)\end{array}$ & $\begin{array}{c}0.012 \\
(0.009)\end{array}$ & 0.58 \\
\hline (5) & Income & $\begin{array}{c}2.261 \\
(3.321)\end{array}$ & $\begin{array}{c}0.077 \\
(0.081)\end{array}$ & $\begin{array}{c}0.556 \\
(0.497)\end{array}$ & $\begin{array}{l}-0.026 \\
(0.013)\end{array}$ & $\begin{array}{l}-0.111 \\
(0.056)\end{array}$ & $\begin{array}{c}0.123 \\
(0.034)\end{array}$ & $\begin{array}{l}-0.007 \\
(0.011)\end{array}$ & 0.47 \\
\hline (5) & Land & $\begin{array}{c}1.546 \\
(1.778)\end{array}$ & $\begin{array}{c}0.011 \\
(0.017)\end{array}$ & $\begin{array}{c}0.298 \\
(0.254)\end{array}$ & $\begin{array}{l}-0.009 \\
(0.003)\end{array}$ & $\begin{array}{l}-0.118 \\
(0.053)\end{array}$ & $\begin{array}{c}0.179 \\
(0.046)\end{array}$ & $\begin{array}{c}0.014 \\
(0.011)\end{array}$ & 0.63 \\
\hline (6) & Income & $\begin{array}{c}4.681 \\
(0.874)\end{array}$ & & & $\begin{array}{l}-0.012 \\
(0.003)\end{array}$ & $\begin{array}{l}-0.142 \\
(0.050)\end{array}$ & $\begin{array}{c}0.124 \\
(0.044)\end{array}$ & & 0.46 \\
\hline (6) & Land & $\begin{array}{c}4.025 \\
(0.626)\end{array}$ & & & $\begin{array}{l}-0.006 \\
(0.001)\end{array}$ & $\begin{array}{l}-0.124 \\
(0.037)\end{array}$ & $\begin{array}{c}0.179 \\
(0.032)\end{array}$ & & 0.58 \\
\hline
\end{tabular}

Dependent variable: Ten year average GDP growth per capita (1991-2001);

\footnotetext{
${ }^{19}$ Our experiment was not designed to check for this effect because savings decision are not modeled.
} 
Next, in Table 5 we present the results with the more encompassing measure of institutional quality (IQ). Institutional quality is measured by combining three measures in the Kaufmann et al. database (i.e. rule of law, regulatory burden and graft). We again transfer the obtained IQ score onto the range from 0 (strong institutional quality) to 10 (weak institutional quality) in order to make the results comparable to those in Table 4.

Table 5. Inequality, institutional quality (IQ) ${ }^{*}$, and Growth

\begin{tabular}{|c|c|c|c|c|c|c|c|c|c|}
\hline & & Constant & Gini & IQ & IQ*Gini & Initial Y & $\operatorname{Inv} / Y$ & Educate & Adj. $\mathrm{R}^{2}$ \\
\hline (1) & Income & $\begin{array}{c}5.704 \\
(1.289)\end{array}$ & $\begin{array}{l}-0.102 \\
(0.032)\end{array}$ & & & & & & 0.13 \\
\hline (1) & Land & $\begin{array}{c}4.578 \\
(0.816)\end{array}$ & $\begin{array}{l}-0.040 \\
(0.012)\end{array}$ & & & & & & 0.19 \\
\hline (2) & Income & $\begin{array}{l}6.067 \\
(1.117)\end{array}$ & $\begin{array}{l}-0.056 \\
(0.040)\end{array}$ & $\begin{array}{l}-0.492 \\
(0.173)\end{array}$ & & & & & 0.25 \\
\hline (2) & Land & $\begin{array}{l}5.499 \\
(0.894)\end{array}$ & $\begin{array}{l}-0.034 \\
(0.011)\end{array}$ & $\begin{array}{l}-0.301 \\
(0.124)\end{array}$ & & & & & 0.23 \\
\hline (3) & Income & $\begin{array}{c}3.314 \\
(1.644)\end{array}$ & $\begin{array}{l}-0.071 \\
(0.031)\end{array}$ & & & $\begin{array}{c}0.005 \\
(0.039)\end{array}$ & $\begin{array}{c}0.139 \\
(0.053)\end{array}$ & $\begin{array}{c}0.008 \\
(0.010)\end{array}$ & 0.36 \\
\hline (3) & Land & $\begin{array}{c}3.140 \\
(0.741)\end{array}$ & $\begin{array}{l}-0.032 \\
(0.010)\end{array}$ & & & $\begin{array}{l}-0.044 \\
(0.034)\end{array}$ & $\begin{array}{c}0.208 \\
(0.046)\end{array}$ & $\begin{array}{c}0.020 \\
(0.009)\end{array}$ & 0.52 \\
\hline (4) & Income & $\begin{array}{l}10.045 \\
(1.575)\end{array}$ & $\begin{array}{l}-0.065 \\
(0.027)\end{array}$ & $\begin{array}{l}-1.013 \\
(0.171)\end{array}$ & & $\begin{array}{l}-0.190 \\
(0.048)\end{array}$ & $\begin{array}{l}0.109 \\
(0.042)\end{array}$ & $\begin{array}{l}-0.008 \\
(0.008)\end{array}$ & 0.51 \\
\hline (4) & Land & $\begin{array}{l}7.604 \\
(1.593)\end{array}$ & $\begin{array}{l}-0.029 \\
(0.009)\end{array}$ & $\begin{array}{l}-0.844 \\
(0.214)\end{array}$ & & $\begin{array}{l}-0.192 \\
(0.049)\end{array}$ & $\begin{array}{l}0.172 \\
0.040\end{array}$ & $\begin{array}{l}0.003 \\
(0.009)\end{array}$ & 0.62 \\
\hline (5) & Income & $\begin{array}{l}5.042 \\
(3.766)\end{array}$ & $\begin{array}{l}0.064 \\
(0.087)\end{array}$ & $\begin{array}{l}0.081 \\
(0.862)\end{array}$ & $\begin{array}{l}-0.028 \\
(0.020)\end{array}$ & $\begin{array}{l}-0.167 \\
(0.055)\end{array}$ & $\begin{array}{l}0.114 \\
(0.045)\end{array}$ & $\begin{array}{l}-0.008 \\
(0.008)\end{array}$ & 0.51 \\
\hline (5) & Land & $\begin{array}{l}4.019 \\
(2.560)\end{array}$ & $\begin{array}{l}0.012 \\
(0.025)\end{array}$ & $\begin{array}{l}-0.064 \\
(0.504)\end{array}$ & $\begin{array}{l}-0.010 \\
(0.006)\end{array}$ & $\begin{array}{l}-0.169 \\
(0.050)\end{array}$ & $\begin{array}{l}0.172 \\
(0.031)\end{array}$ & $\begin{array}{l}0.008 \\
(0.010)\end{array}$ & 0.63 \\
\hline (6) & Income & $\begin{array}{l}6.053 \\
(1.079)\end{array}$ & & & $\begin{array}{l}-0.021 \\
(0.004)\end{array}$ & $\begin{array}{l}-0.186 \\
(0.050)\end{array}$ & $\begin{array}{l}0.136 \\
(0.047)\end{array}$ & & 0.51 \\
\hline (6) & Land & $\begin{array}{l}4.302 \\
(0.588)\end{array}$ & & & $\begin{array}{l}-0.009 \\
(0.001)\end{array}$ & $\begin{array}{l}-0.112 \\
(0.032)\end{array}$ & $\begin{array}{l}0.184 \\
(0.030)\end{array}$ & & 0.63 \\
\hline
\end{tabular}

Dependent variable: Ten year average GDP growth per capita (1991-2001); Standard errors in parentheses.

${ }^{*}$ IQ has been measured such that higher quantitative values represent a lower standard.

Notice from Table 5 that the size of the negative effect of bad institutional quality on growth, if measured in isolation, rows (2), is even larger than in Table 4. Apart from that, the results in Table 5 are strikingly similar to those in Table 4. In particular, for this specification of institutional quality, the interaction term of IQ and the Gini coefficient is statistically significant negative again. See row (6) of the table. Thus, the negative effect of procedural fairness on growth appears to be rather robust: the combined effect of large inequality and 
weak institutions (high IQ) on the growth rate is strongly negative. Moreover, also for this specification both the IQ measure and the Gini coefficient can change signs and become insignificant after including the interaction term. Therefore, the finding that inequality is harming growth only when bad institutions are in place is replicated with this alternative measure of institutional quality.

\section{Conclusions}

Both the empirical and the theoretical research on the relationship between inequality and growth have come to ambiguous results, sometimes finding a positive, sometimes a negative, and sometimes varying correlations (Aghion et al., Barro). It seems that more theoretical and experimental work on the behavioral micro-foundations will be necessary to untangle the complicated mechanisms that govern the relationship between inequality and growth. In a first paper, we put Knack and Keefer's conjecture that inequality destroys "social capital" to a direct experimental test, but found no evidence whatsoever in support of it: the observed level of cooperation was independent of the implemented degree of inequality (Sadrieh and Verbon). Given this result, it seems evident that something more than inequality by itself is needed to observe the collapse of societal cooperation.

The hypothesis we started this paper with is that the degree of cooperation not only depends on the degree of inequality, but also on its genesis. To be able to examine this hypothesis, we first introduce a model that allows for efficient, mutual cooperation in an unequal income setting. We then conduct laboratory experiments using this model in two variants. In the nature variant, the degree of inequality (either high or low inequality) is selected by the experimenter at random. In the dictator variant, the degree of inequality is selected by the only "rich" individual in the 3-person economy. The results of the experiment are as 
conjectured: inequality is only detrimental to cooperation and, thus, to growth, when it is deliberately chosen by the rich dictator. As in the previous experiment, inequality has no effect when it is brought on by a random draw (i.e. by a "fair procedure"). Our results are in line with the results found by Bolton et al., who tested experimentally the effect of the procedures used on the acceptability of choices in games with biased outcomes. One of their conclusions is that biased allocations are less acceptable for those who are on the short end of things when chosen by a biased procedure. Within our experimental setting the conclusion is that inequality brought about by an unfair procedure (i.e. the dictator treatment) will have a negative effect on the willingness to cooperate. Inequality in societies with weak institutions will, therefore, be detrimental to growth.

In an attempt to give these micro-level results some macroeconomic substance, we ran simple regressions of cross-country data on per-capita growth, inequality, and measures of institutional strength, including a number of macroeconomic control variables that are commonly found in the empirical growth literature. We used two measures of institutional strength (or weakness) in turn (i.e. corruption and a more composite measure, including rule of law, regulatory burden and graft). For both measures of institutional quality, the regressions vindicate one of our central experimental results: that fair procedures strongly determine the willingness to cooperate, and thus growth, in countries. With all due caveats in interpreting such simple regression models, the effect seems to be robust and strong enough to allow confidence in its support for our hypothesis. The adverse effect on growth is entirely captured by the interaction term of inequality and the institutional quality, leaving no independent role for inequality or corruption.

Our result strongly supports the spreading view that the real output effects of inequality are linked to the institutions governing the economy. The special contribution of our paper is to 
show a new channel through which this interaction may be effective. The channel we suggest and examine is that of voluntary cooperation in a social dilemma type situation. The idea is that a substantial part of the effort that is put into production by the labor force is nonverifiable and, hence, will be dependent on the individual's trust and emotional attachment to the society. Clearly, these may both be severely damaged by inequality that results from the actions of a self-serving dictator, but not by inequality emerging from fair competition.

\section{References}

Abbink, K., Irlenbusch, B., Renner E., 2000. The moonlighting game - an experimental study on reciprocity and retribution. Journal of Economic Behavior and Organization 42, 265-277.

Aghion, P., Caroli, E., García-Peñalosa, C., 1999. Inequality and economic growth: the perspective of the new growth theories. Journal of Economic Literature 37, 1615-1660.

Barro, R J., 2000. Inequality and growth in a panel of countries. Journal of Economic Growth 5, 5-32.

Blount, S., 1995. When social outcomes aren't fair: the effect of causal attributions on preferences. Organizational Behavior and Human Decision Processes 63, 131-144.

Bolton, G.E., Brandts, J., Ockenfels A., 2005. Fair procedures: evidence from games involving lotteries. Economic Journal 115, 1054-1076.

Bosman, R., Van Winden, F., 2002. Emotional hazard in a power-to-take game experiment. Economic Journal $112,147-169$.

Deininger, K., Squire, L., 1996. A new data set measuring income inequality. World Bank Economic Review 10, $565-591$.

Deininger, K., Olinto, P., 2000. Asset distribution, inequality, and growth. World Bank Policy research Working Paper 2375.

Dufwenberg, M., Kirchsteiger. G., 2004. A theory of sequential reciprocity. Games and Economic Behavior 47, 268-298.

Ehrlich, I., Lui, F.T., 1999. Bureaucratic corruption and endogenous economic growth. Journal of Political Economy 107, S270-S293.

Falk, A., Fehr, E., Fischbacher, U., 2000. Testing theories of fairness. Working paper 63, University of Zurich (forthcoming in Games and Economic Behavior).

Fehr, E., Rockenbach, B., 2003. Detrimental effects of sanctions on human altruism. Nature 422, 137-140.

Galbraith, J.K., Kum, H., 2005. Estimating the inequality of household incomes: a statistical approach to the creation of a dense and consistent global data set. Review of Income and Wealth 51, 115-143. 
Glaeser, E., Scheinkman, J., Schleifer, A., 2003. The injustice of inequality. Journal of Monetary Economics 50, 199-222.

Güth, W., 1995. An evolutionary approach to explaining cooperative behavior by reciprocal incentives. International Journal of Game Theory 24, 323-344.

Hoffman, E., McCabe, K., Shachat, L., Smith, V., 1994. Preferences, property rights, and anonymity in bargaining games. Games and Economic Behavior 7, 346-380.

Kaufmann, D., Kraay, A., Zoido-Lobatón, P., 1999. Aggregating governance indicators. World Bank, Policy Research Working Paper 2195.

Knack, S., Keefer, P., 1997. Does social capital have an economic payoff. Quarterly Journal of Economics 112 , 213-214.

Lambsdorff, J.G., 2002. Background paper to the 2002 corruption perceptions index - framework document 2002. Transparency International and University of Göttingen. (http://www.transparency.org)

Li, H., Xu, L.C., Zou, H-F., 2000. Corruption, income distribution, and growth. Economics and Politics 12, $155-$ 182.

Lundberg, M., Squire, L., 2003. The simultaneous evolution of growth and inequality. Economic Journal 113, 326-344.

Mauro, P., 1995. Corruption and Growth. Quarterly Journal of Economics 110, 681-712.

Rabin, M., 1993. Incorporating fairness into game theory and economics. American Economic Review 83, 1281 1302.

Roth, A.E., 1995. Bargaining experiments, in Kagel, J., Roth, A.E., (Eds.). Handbook of Experimental Economics. Princeton, NJ: Princeton University Press, 253-348.

Sadrieh, A., Verbon, H.A.A., 2006. Inequality, trust and growth. European Economic Review 50, 1197-1222. 


\section{Appendix A - Instructions}

This is an experiment on economic decision-making within groups over 2 periods. These instructions explain the workings of the experiment and if you follow them carefully, you may earn a considerable amount of money, which will be paid to you in cash. You are expected to make decisions on your own without consulting other participants. So, please, do not communicate with the other participants. Otherwise, we might have to stop the experiment.

How does this experiment work? Each group consists of 3 participants, so you are in a group with 2 others in the room but you will not be able to identify your group members. The group members will be indicated by a color: Red, Blue, and Green. For the purposes of this instruction we will just talk of "your group members". At the beginning of period 1, each group member has some amount of start capital. At least one of your group members will have a start capital that differs from yours. The start capital that you get can be relatively low, or it can be relatively high. Which of the two will hold for you will be decided by the Red player, who in both cases will have the highest start capital in your group. Of course, if you happen to be the Red player you will decide on your own and the others' start capital.

Whatever your start capital may be you can enlarge your start capital over two periods by making a decision each period. These decisions determine the return that you are earning on your capital. The development of your capital does not only depend on your own decisions, but also on the decisions of the other members of your group. Based on these decisions, at the end of the $2^{\text {nd }}$ period you will have accumulated a certain amount of final capital. From this final capital the start capital will be subtracted resulting in the payoffs that determine your earnings out of this experiment.

In each period, each group member chooses simultaneously one of two options: A or B. As will become clear from the payoff sheets to be discussed in a moment, if all group members choose B, the capital of all group members will grow more than if all choose A. However, if you choose B alone, while the other group members choose A, your capital will grow less while the others' capital will grow more, than if you had chosen A.

Consider the $\mathbf{2}$ payoff sheets on your desk. These sheets contain important information on your payoff during the experiment. However, if we start playing the experiment, only 1 of the two payoff sheets are relevant for your decisions. Which payoff tables that will be, depends on the Red player's decision. If the Red player chooses the start capital of 220 for him- or herself and 40 for Blue and Green, payoff sheet 1 is relevant to all of you. But if the Red player chooses the start capital of 120 for him- or herself and 90 for Blue and Green, payoff sheets 2 is relevant to all of you.

Let us assume that a payoff sheet 1 is relevant. But, the same reasoning applies if payoff sheet 2 is relevant. For that case, just change in the following, payoff sheet 1 into payoff sheet 2 . When you decide on A or B in the $1^{\text {st }}$ period, you do not know your group members' $1^{\text {st }}$ period choices. However, if you choose A in the $1^{\text {st }}$ period, then, whatever the choices of your group members, payoff sheet 1 LEFT is from then on relevant for you. On the other hand, if you choose B in the $1^{\text {st }}$ period, payoff sheet 1 RIGHT is relevant. So, a choice between A or B is a choice between payoff sheets 1 LEFT and 1 RIGHT. The structure of payoff sheets 1 LEFT and 1 RIGHT is 
identical. It suffices, therefore, to consider one of those payoff sheets only. Let us look at payoff sheet 1 LEFT, where your $1^{\text {st }}$ period decision is A. Omit for a moment the table at the center of the page, saying, "If 1 st period choice was Reset".

Payoff sheet 1 LEFT shows 4 payoff tables. These tables give the possible payoff you and your group members will generate, depending on you and your group members' $2^{\text {nd }}$ period choices. The letters in the rows of those tables show the decisions of your group (including yourself) in period 2 and the numbers show the final payoff for you and your group members corresponding to these decisions. The first of those numbers is always your final payoff, while the next two numbers are those of your group members. Which of these four tables is relevant for you will depend on the $1^{\text {st }}$ period choice of your group members. If they both choose A, then the first table saying "If $1^{\text {st }}$ period choice was (A, A, A)" is relevant, but if the first other group member chooses A and the other one chooses B the second table saying "If $1^{\text {st }}$ period choice was (A, A, B)" is relevant. The other two tables will be relevant, if the first other group member chooses $\mathrm{B}$, and the other chooses $\mathrm{A}$, or when they both choose $\mathrm{B}$, respectively. In payoff sheet 1 RIGHT you will notice that the first letter in the headings of the payoff tables is not $\mathrm{A}$, but $\mathrm{B}$, corresponding with a $1^{\text {st }}$ period decision of yours of $\mathrm{B}$ instead of $\mathrm{A}$.

Once all 1st period decisions on A or B are made, the experimenter will collect all the decision sheets, and return them with the decisions of your group members on A or B included. Then you will know exactly which payoff table on the left-hand side of the payoff sheet is relevant for you. Notice that in your payoff table the payoffs of your group members are shown as well. To help you the experimenter will mark this table with a cross.

After all group members know their payoff table, each group member is given a reset option. If one group member chooses to reset, then the capital of every group member after the $1^{\text {st }}$ period will be reset to the start capital. What this implies for the payoff is shown by the "Reset" table at CENTER of Payoff sheet 1. You or one of your group members might prefer the Reset option over and above the relevant table at the left-hand side of the Payoff sheet.

The experimenter will communicate to all group members whether there has been a reset, or not. If not, then the table at the left-hand side that was marked with a cross will be the table that is decisive for your final payoff. But, if there has been a reset, table CENTER on the page is decisive.

After the decision whether or not to reset, the $2^{\text {nd }}$ period starts. In the $2^{\text {nd }}$ period again each group member chooses simultaneously from one of two options: A or B. Like in the $1^{\text {st }}$ period, when you decide on A or B, you do not know your group members' $2^{\text {nd }}$ period choices. If you choose A, then the first four rows in your relevant table shows you the possible payoffs for you and your group members. If you choose B, then the last four rows in your relevant table show you the possible payoffs for you and your group members. Which of those four rows is decisive for your final payoff depends on your group members.

After everyone has decided on A or B, the experimenter will collect the decision sheets and return them with the decision of your group members. Then you will know exactly which row in your payoff table is relevant for you. To help you the experimenter will mark this row with a cross. Again, after all group members have decided for A or B in the $2^{\text {nd }}$ period, each group member is given a reset option. If one group member chooses to reset, then the capital of every group member after the $2^{\text {nd }}$ period will be reset to the start capital of the $2^{\text {nd }}$ period. What this implies for the final payoff is shown by the bottom row of the table saying, "Reset". You or one of your group 
members might prefer the Reset option over and above the relevant rows in your payoff table. Notice that if you are already in the Reset table, a reset choice in your group will lead to zero final payoffs for all group members. This is due to a choice for reset in the $1^{\text {st }}$ and the $2^{\text {nd }}$ period, which implies that the final capital for you and your group members equals the start capital. As a result the payoff for any of your group members, including yourself, equals the show-up fee.

The experimenter will collect all decisions on the reset option and thereafter communicate to all group members whether there has been a reset, or not. If not, then the row in the table that was marked with a cross will be decisive for your final payoff. But, if there has been a reset, the bottom row of the table is decisive for your final payoff.

The final payoff will be exchanged into earnings at the rate of 20 cent per point. Your total earnings from the experiment are paid to you at the end of the experiment in cash. Additionally, each of you will receive a fixed payment of 3 Euro for participation in the experiment.

Summarizing. First the Red player decides on the distribution of capital. That choice determines whether the Payoff sheet 1 or Payoff sheet 2 is used. Your own $1^{\text {st }}$ period choice determines whether sheet 1 LEFT or sheet 1 RIGHT (or, sheet 2 LEFT or sheet 2 RIGHT) is decisive for your and the others' payoff. The $1^{\text {st }}$ period choices of your group members fix the table on the left/right-hand side of the relevant payoff sheet. However, if you or one of your group members chooses to reset in the $1^{\text {st }}$ period, the "Reset" table on the center of the sheet is decisive. The $2^{\text {nd }}$ period choices of you and your group members determine which row in the chosen table is going to be decisive for the payoffs. However, if any one in your group (including yourself) has opted for a reset in the $2^{\text {nd }}$ period, the bottom row in the chosen table sets the payoffs for all group members.

Practice rounds. Before running the actual experiments, we give you the opportunity to have some practice. For these practice rounds you can use the payoff sheets on your desk, which are also used for the actual experiment. Moreover, you can use the practice sheets, which are handed out to you now. You will not be paid for the results of these rounds, these rounds are only meant to let you become acquainted with the structure of the experiment. First, we play two practice rounds together for payoff sheets 1. After that, we play two practice rounds together for payoff sheets 2 .

During these rounds I announce what you and your group members are hypothetically doing. This information is indicated on your group-practice sheets by A1.1, etc. You indicate on your guided-practice sheets which payoff sheets, tables, or payoffs are relevant behind the questions Q1.1. etc. 


\section{Appendix B - Payoff Sheets}

Payoff sheet of the rich in the high inequality treatment (Gini $=.6)$.

The other payoff sheets contained exactly the same information, but the columns of the tables were sorted in a way that had each subject's own payoff in the first column.

\begin{tabular}{|c|c|c|c|c|c|c|c|c|c|c|c|c|c|c|c|}
\hline \multicolumn{6}{|c|}{$\begin{array}{l}\text { PAYOFF SHEET LEFT } \\
\text { START CAPITAL }(220,40,40) \\
\text { Payoff tables, if your } 1^{\text {st }} \text { choice was A }\end{array}$} & \multicolumn{4}{|c|}{$\begin{array}{l}\text { PAYOFF SHEET CENTER } \\
\text { START CAPITAL }(220,40,40) \\
\text { If } 1^{\text {st }} \text { period choice was Reset }\end{array}$} & \multicolumn{6}{|c|}{$\begin{array}{l}\text { PAYOFF SHEET RIGHT } \\
\text { START CAPITAL }(220,40,40) \\
\text { Payoff tables, if your } 1^{\text {st }} \text { choice was B }\end{array}$} \\
\hline \multicolumn{6}{|c|}{ If $1^{\text {st }}$ period choice was $(A, A, A)$} & & & & & \multicolumn{6}{|c|}{ If $1^{\text {st }}$ period choice was $(\mathrm{B}, \mathrm{A}, \mathrm{A})$} \\
\hline Red & Green & Blue & Red & Green & Blue & & & & & Red & Green & Blue & Red & Green & Blue \\
\hline A & $\mathrm{A}$ & A & 44 & 26 & 26 & & & & & & A & A & 39 & 34 & 34 \\
\hline A & A & $\mathrm{B}$ & 84 & 35 & 19 & & & & & & A & $\mathrm{B}$ & 78 & 44 & 27 \\
\hline A & $\mathrm{B}$ & A & 84 & 19 & 35 & & & & & A & $\mathrm{B}$ & A & 78 & 27 & 44 \\
\hline A & $\mathrm{B}$ & $\mathrm{B}$ & 123 & 28 & 28 & & & & & & $\mathrm{~B}$ & $\mathrm{~B}$ & 117 & 37 & 37 \\
\hline B & A & A & 36 & 35 & 35 & & & & & B & A & A & 32 & 44 & 44 \\
\hline B & A & $\mathrm{B}$ & 76 & 43 & 28 & & & & & B & A & B & 71 & 54 & 37 \\
\hline B & $\mathrm{B}$ & A & 76 & 28 & 43 & & & & & B & B & A & 71 & 37 & 54 \\
\hline \multirow[t]{2}{*}{ B } & $\mathrm{B}$ & $\mathrm{B}$ & 116 & 36 & 36 & & & & & B & B & B & 110 & 47 & 47 \\
\hline & Reset & & 20 & 12 & 12 & & & & & & Reset & & 13 & 18 & 18 \\
\hline \multicolumn{6}{|c|}{ If $1^{\text {st }}$ period choice was $(A, A, B)$} & \multicolumn{4}{|c|}{ If $1^{\text {st }}$ period choice was Reset } & \multicolumn{6}{|c|}{ If $1^{\text {st }}$ period choice was $(B, A, B)$} \\
\hline Red & Green & Blue & Red & Green & Blue & Red Green Blue & Red & Gree & Blue & Red & Green & Blue & Red & Green & Blue \\
\hline A & $\mathrm{A}$ & A & 81 & 35 & 19 & A $\quad$ A $\quad$ A & 20 & 12 & 12 & A & A & A & 77 & 43 & 27 \\
\hline A & $\mathrm{A}$ & $\mathrm{B}$ & 127 & 44 & 11 & A & 56 & 18 & 5 & A & A & B & 122 & 54 & 19 \\
\hline A & B & A & 127 & 27 & 26 & B & 56 & 5 & 18 & A & B & A & 122 & 35 & 36 \\
\hline A & B & B & 173 & 36 & 18 & B & 93 & 12 & 12 & A & B & B & 167 & 46 & 28 \\
\hline B & A & A & 73 & 44 & 26 & A & 13 & 18 & 18 & B & A & A & 69 & 54 & 36 \\
\hline B & A & $\mathrm{B}$ & 119 & 54 & 18 & A & 50 & 25 & 12 & B & A & B & 114 & 65 & 28 \\
\hline B & B & A & 119 & 36 & 34 & B & 50 & 12 & 25 & B & B & A & 114 & 46 & 44 \\
\hline \multirow[t]{2}{*}{ B } & B & B & 165 & 46 & 26 & B & 87 & 19 & 19 & B & B & B & 159 & 56 & 36 \\
\hline & Reset & & 56 & 18 & 5 & Reset & 0 & 0 & 0 & & Reset & & 50 & 25 & 12 \\
\hline \multicolumn{6}{|c|}{ If $1^{\text {st }}$ period choice was $(\mathrm{A}, \mathrm{B}, \mathrm{A})$} & & & & & \multicolumn{6}{|c|}{ If $1^{\text {st }}$ period choice was $(B, B, A)$} \\
\hline Red & Green & Blue & Red & Green & Blue & & & & & Red & Green & Blue & Red & Green & Blue \\
\hline A & A & A & 81 & 19 & 35 & & & & & & A & A & 77 & 27 & 43 \\
\hline A & A & $\mathrm{B}$ & 127 & 26 & 27 & & & & & & A & $\mathrm{B}$ & 122 & 36 & 35 \\
\hline A & $\mathrm{B}$ & A & 127 & 11 & 44 & & & & & & $\mathrm{~B}$ & A & 122 & 19 & 54 \\
\hline A & B & B & 173 & 18 & 36 & & & & & A & B & B & 167 & 28 & 46 \\
\hline B & A & A & 73 & 26 & 44 & & & & & B & A & A & 69 & 36 & 54 \\
\hline B & A & B & 119 & 34 & 36 & & & & & B & A & B & 114 & 44 & 46 \\
\hline B & B & A & 119 & 18 & 54 & & & & & B & B & A & 114 & 28 & 65 \\
\hline \multirow[t]{2}{*}{ B } & B & B & 165 & 26 & 46 & & & & & B & B & B & 159 & 36 & 56 \\
\hline & Reset & & & 5 & 18 & & & & & & Reset & & 50 & 12 & 25 \\
\hline \multicolumn{6}{|c|}{ If $1^{\text {st }}$ period choice was $(A, B, B)$} & \multirow{11}{*}{\multicolumn{4}{|c|}{$\begin{array}{l}\text { The tables on the left and right -hand } \\
\text { side are decisive for your payoff if } \\
\text { there has been no reset in the } 1^{\text {st }} \text { period. } \\
\text { If there has been a reset, the CENTER } \\
\text { table determines your payoff. The last } \\
\text { row of any table will be the payoff if } \\
\text { there has been a reset in the } 2^{\text {nd }} \text { period. } \\
\text { Letters in the rows are } 2^{\text {nd }} \text {-period } \\
\text { choices of you and your group } \\
\text { members Green and Blue; Numbers are } \\
\text { the corresponding payoffs for you, } \\
\text { Green and Blue. }\end{array}$}} & \multicolumn{6}{|c|}{ If $1^{\text {st }}$ period choice was $(B, B, B)$} \\
\hline Red & Green & Blue & Red & Green & Blue & & & & & & Green & Blue & Red & Green & Blue \\
\hline A & A & A & 119 & 27 & 27 & & & & & & A & A & 115 & 35 & 35 \\
\hline A & A & $\mathrm{B}$ & 171 & 36 & 18 & & & & & & A & $\mathrm{B}$ & 166 & 45 & 27 \\
\hline A & $\mathrm{B}$ & A & 171 & 18 & 36 & & & & & & $\mathrm{~B}$ & A & 166 & 27 & 45 \\
\hline A & B & $\mathrm{B}$ & 223 & 27 & 27 & & & & & & $\mathrm{~B}$ & $\mathrm{~B}$ & 217 & 36 & 36 \\
\hline B & A & A & 110 & 36 & 36 & & & & & & A & A & 106 & 45 & 45 \\
\hline B & A & B & 162 & 44 & 27 & & & & & & A & B & 157 & 55 & 36 \\
\hline B & B & A & 162 & 27 & 44 & & & & & B & $\mathrm{B}$ & A & 157 & 36 & 55 \\
\hline B & B & B & 215 & 36 & 36 & & & & & & $\mathrm{~B}$ & B & 208 & 46 & 46 \\
\hline & Reset & & 93 & 12 & 12 & & & & & & Reset & & 87 & 19 & 19 \\
\hline
\end{tabular}


Payoff sheet of the rich in the low inequality treatment $(\mathrm{Gini}=.1)$.

The other payoff sheets contained exactly the same information, but the columns of the tables were sorted in a way that had each subject's own payoff in the first column.

\begin{tabular}{|c|c|c|c|c|c|c|c|c|c|c|c|c|c|c|c|c|}
\hline \multirow{3}{*}{\multicolumn{6}{|c|}{$\begin{array}{l}\text { PAYOFF SHEET LEFT } \\
\text { START CAPITAL }(120,90,90) \\
\text { Payoff tables, if your } 1^{\text {st }} \text { choice was A }\end{array}$}} & \multirow{3}{*}{\multicolumn{5}{|c|}{$\begin{array}{l}\text { PAYOFF SHEET CENTER } \\
\text { START CAPITAL }(120,90,90) \\
\text { If } 1^{\text {st }} \text { period choice was Reset }\end{array}$}} & \multirow{3}{*}{\multicolumn{6}{|c|}{$\begin{array}{l}\text { PAYOFF SHEET RIGHT } \\
\text { START CAPITAL }(120,90,90) \\
\text { Payoff tables, if your } 1^{\text {st }} \text { choice was B }\end{array}$}} \\
\hline & & & & & & & & & & & & & & & & \\
\hline & & & & & & & & & & & & & & & & \\
\hline \multicolumn{6}{|c|}{ If $1^{\text {st }}$ period choice was $(A, A, A)$} & & & & & & \multicolumn{6}{|c|}{ If $1^{\text {st }}$ period choice was $(B, A, A)$} \\
\hline Red & Green & Blue & Red & Green & Blue & & & & & & Red & Green & Blue & Red & Green & Blue \\
\hline A & A & A & 53 & 47 & 47 & & & & & & & A & A & 47 & 64 & 64 \\
\hline A & A & B & 77 & 65 & 39 & & & & & & & A & B & 70 & 85 & 56 \\
\hline A & B & A & 77 & 39 & 65 & & & & & & A & B & A & 70 & 56 & 85 \\
\hline A & B & B & 101 & 58 & 58 & & & & & & A & B & B & 93 & 77 & 77 \\
\hline B & A & A & 45 & 65 & 65 & & & & & & B & A & A & 39 & 85 & 85 \\
\hline B & A & B & 69 & 84 & 58 & & & & & & B & A & B & 62 & 106 & 77 \\
\hline B & B & A & 69 & 58 & 84 & & & & & & B & B & A & 62 & 77 & 106 \\
\hline \multirow[t]{2}{*}{ B } & B & B & 93 & 76 & 76 & & & & & & B & B & B & 85 & 98 & 98 \\
\hline & Reset & & 24 & 21 & 21 & & & & & & & Reset & & 18 & 36 & 36 \\
\hline \multicolumn{6}{|c|}{ If $1^{\text {st }}$ period choice was $(A, A, B)$} & \multicolumn{5}{|c|}{ If $1^{\text {st }}$ period choice was Reset } & \multicolumn{6}{|c|}{ If $1^{\text {st }}$ period choice was $(B, A, B)$} \\
\hline Red & Green & Blue & Red & Green & Blue & Red Green & Blue & Red & Green & Blue & Red & Green & Blue & Red & Green & Blue \\
\hline A & A & A & 76 & 65 & 40 & A $\quad$ A & A & 24 & 21 & 21 & & A & A & 71 & 82 & 58 \\
\hline A & $\mathrm{A}$ & $\mathrm{B}$ & 103 & 86 & 32 & A & $\mathrm{B}$ & 44 & 36 & 15 & & A & $\mathrm{B}$ & 97 & 106 & 50 \\
\hline A & $\mathrm{B}$ & A & 103 & 56 & 58 & B & A & 44 & 15 & 36 & & B & A & 97 & 73 & 78 \\
\hline A & B & B & 131 & 77 & 50 & B & B & 64 & 30 & 30 & & B & B & 123 & 97 & 69 \\
\hline B & A & A & 68 & 86 & 58 & A & A & 18 & 36 & 36 & B & A & A & 62 & 106 & 78 \\
\hline B & A & B & 95 & 107 & 50 & A & B & 38 & 51 & 30 & B & A & B & 88 & 129 & 69 \\
\hline B & B & A & 95 & 77 & 75 & B & A & 38 & 30 & 51 & B & B & A & 88 & 97 & 98 \\
\hline \multirow[t]{2}{*}{ B } & B & B & 122 & 98 & 67 & B & B & 58 & 45 & 45 & B & B & B & 114 & 120 & 89 \\
\hline & Reset & & 44 & 36 & 15 & Reset & & 0 & 0 & 0 & & Reset & & 38 & 51 & 30 \\
\hline \multicolumn{6}{|c|}{ If $1^{\text {st }}$ period choice was $(\mathrm{A}, \mathrm{B}, \mathrm{A})$} & \multirow{11}{*}{\multicolumn{5}{|c|}{$\begin{array}{l}\text { The tables on the left and right -hand } \\
\text { side are decisive for your payoff if } \\
\text { there has been no reset in the } 1^{\text {st }} \text { period. } \\
\text { If there has been a reset, the CENTER } \\
\text { table determines your payoff. The last } \\
\text { row of any table will be the payoff if } \\
\text { there has been a reset in the } 2^{\text {nd }} \text { period. } \\
\text { Letters in the rows are } 2^{\text {nd }} \text {-period } \\
\text { choices of you and your group } \\
\text { members Green and Blue; Numbers are } \\
\text { the corresponding payoffs for you, } \\
\text { Green and Blue. }\end{array}$}} & \multicolumn{6}{|c|}{ If $1^{\text {st }}$ period choice was $(B, B, A)$} \\
\hline Red & Green & Blue & Red & Green & Blue & & & & & & Red & Green & Blue & Red & Green & Blue \\
\hline & A & A & 76 & 40 & 65 & & & & & & A & A & A & 71 & 58 & 82 \\
\hline A & A & B & 103 & 58 & 56 & & & & & & A & A & B & 97 & 78 & 73 \\
\hline A & B & A & 103 & 32 & 86 & & & & & & A & B & A & 97 & 50 & 106 \\
\hline A & B & B & 131 & 50 & 77 & & & & & & A & B & B & 123 & 69 & 97 \\
\hline B & A & A & 68 & 58 & 86 & & & & & & B & A & A & 62 & 78 & 106 \\
\hline B & A & B & 95 & 75 & 77 & & & & & & B & A & B & 88 & 98 & 97 \\
\hline B & B & A & 95 & 50 & 107 & & & & & & B & B & A & 88 & 69 & 129 \\
\hline \multirow[t]{2}{*}{ B } & $\mathrm{B}$ & B & 122 & 67 & 98 & & & & & & B & B & B & 114 & 89 & 120 \\
\hline & Reset & & 44 & 15 & 36 & & & & & & & Reset & & 38 & 30 & 51 \\
\hline \multicolumn{6}{|c|}{ If $1^{\text {st }}$ period choice was $(A, B, B)$} & \multirow{11}{*}{\multicolumn{5}{|c|}{$\begin{array}{l}\text { The tables on the left and right -hand } \\
\text { side are decisive for your payoff if } \\
\text { there has been no reset in the } 1^{\text {st }} \text { period. } \\
\text { If there has been a reset, the CENTER } \\
\text { table determines your payoff. The last } \\
\text { row of any table will be the payoff if } \\
\text { there has been a reset in the } 2^{\text {nd }} \text { period. } \\
\text { Letters in the rows are } 2^{\text {nd }} \text {-period } \\
\text { choices of you and your group } \\
\text { members Green and Blue; Numbers are } \\
\text { the corresponding payoffs for you, } \\
\text { Green and Blue. }\end{array}$}} & \multicolumn{6}{|c|}{ If $1^{\text {st }}$ period choice was $(\mathrm{B}, \mathrm{B}, \mathrm{B})$} \\
\hline Red & Green & Blue & Red & Green & Blue & & & & & & Red & Green & Blue & Red & Green & Blue \\
\hline & A & A & 99 & 58 & 58 & & & & & & & A & A & 93 & 76 & 76 \\
\hline & A & $\mathrm{B}$ & 129 & 78 & 50 & & & & & & & A & $\mathrm{B}$ & 123 & 99 & 67 \\
\hline & $\mathrm{B}$ & A & 129 & 50 & 78 & & & & & & & $\mathrm{~B}$ & A & 123 & 67 & 99 \\
\hline A & B & B & 160 & 70 & 70 & & & & & & A & B & B & 153 & 89 & 89 \\
\hline B & A & A & 90 & 78 & 78 & & & & & & B & A & A & 84 & 99 & 99 \\
\hline B & A & $\mathrm{B}$ & 121 & 98 & 70 & & & & & & & A & B & 114 & 121 & 89 \\
\hline B & B & A & 121 & 70 & 98 & & & & & & & B & A & 114 & 89 & 121 \\
\hline B & $\mathrm{B}$ & B & 151 & 89 & 89 & & & & & & B & $\mathrm{B}$ & B & 143 & 112 & 112 \\
\hline & Reset & & 64 & 30 & 30 & & & & & & & Reset & & 58 & 45 & 45 \\
\hline
\end{tabular}


Appendix C - Decision Sheet

Decision Sheet for period 1: You Are BLUE.

$\begin{array}{ccl}\text { My start capital } & \text { Start capital for GREEN } & \text { Start capital for RED } \\ 70 & 70 & 160\end{array}$

My choice in period 1(Please indicate with mark " $\mathrm{X}$ " in the box)

A

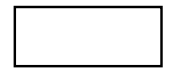

B

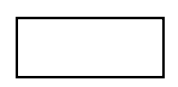

Make a decision up to this point and wait for the experimenter.

To be filled by the experimenter,

Choice of Blue A

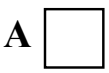

B

Choice of Green $\mathbf{A}$

B

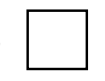

Choice of Red

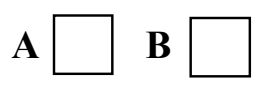

Based on these choices your payoff table is the table saying "If first-period choice was ( , , ). Do you want to reset and, as a result, switch to the "Reset" table as the table that is decisive for your final payoff? Indicate your choice by marking " $\mathbf{X}$ " in the box.

Reset $\square$ Do not reset $\square$

Make a decision up to this point and wait for the experimenter

To be filled by the experimenter

Choice of Blue Reset YES $\square$ NO $\square$

Choice of Green Reset YES $\square$ NO $\square$

Choice of Red Reset YES $\square$ NO $\square$ 
Decision Sheet for period 2: You Are BLUE.

My payoff table is the table: "If $1^{\text {st }}$ period was $(\quad, \quad, \quad$ )" on payoff sheet ....

My choice (Blue) in period 2 (Please indicate with mark " $\mathrm{X}$ " in the box)

A

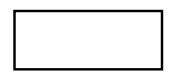

B

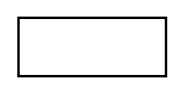

Make a decision up to this point and wait for the experimenter.

To be filled by the experimenter.

Choice of Blue

A

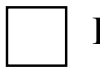

B $\square$

Choice of Green

A

B

Choice of Red

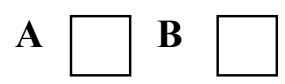

Based on these your payoff is given by the row ( , , ), and the corresponding payoffs for you and your group members is (

Do you want to reset and, as a result, switch to the "Reset" row in your table as the row that is decisive for your final payoff? Indicate your choice by marking " $\mathbf{X}$ " in the box.

Reset

Do not reset

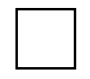

Make a decision up to this point and wait for the experimenter

To be filled out by the experimenter

Choice of Blue Reset YES $\square$

NO $\square$

Choice of Green Reset YES

NO

Choice of Red Reset YES

NO

The final payoff for you and your group members is (

YOUR EARNINGS: $\quad$ XX show-up fee $+\mathrm{xx}$ Cent $\mathrm{x}$ payoff 